\title{
OPTIMALISASI LABORATORIUM IPA UNTUK MENINGKATKAN MINAT BELAJAR SISWA DI SMP SWASTA ISLAM TERPADU IQRA' MEDAN
}

\author{
Muhammad Zulham Efendi Sinaga ${ }^{1)}$, Yuan Alfinsyah Sihombing ${ }^{2)}$ dan Aghni Syahmarani ${ }^{3)}$ \\ ${ }^{1)}$ Departemen Kimia, Fakultas Matematika dan Ilmu Pengetahuan Alam, Universitas Sumatera Utara \\ Email: m.zulham.effendi@usu.ac.id \\ ${ }^{2)}$ Departemen Fisika, Fakultas Matematika dan Ilmu Pengetahuan Alam, Universitas Sumatera Utara \\ Email: m.zulham.effendi@usu.ac.id \\ ${ }^{3)}$ Departemen Matematika, Fakultas Matematika dan Ilmu Pengetahuan Alam, Universitas Sumatera Utara \\ Email: syahmarani.aghni@gmail.com
}

\begin{abstract}
ABSTRAK
Laboratorium merupakan sarana yang sangat penting keberadaaannya di satuan pendidikan dasar dan menengah. Laboratorium dengan aktivitas praktikumnya dapat membantu pemahaman siswa terhadap konsep yang dipelajarinya di kelas sehingga meningkatkan minat belajar siswa terhadap sains. Salah satu kompetensi dalam proses belajar mengajar adalah kemampuan siswa memecahkan masalah di kehidupan sehari-hari. Ini bisa tercapai dengan bantuan laboratorium beserta alat peraga yang tersedia di sekolah. Kemampuan psikomotorik siswa akan terasah dalam memecahkan masalah-masalah yang berkaitan dengan konsep sains. Kegiatan pengabdian kepada masyarkat dilakukan dengan beberapa metode yaitu survey awal terhadap permasalahan mitra, merancang alat peraga dan peralatan praktikum, praktikum sederhana di laboratorium danmembuat buku penuntun praktikum. Pada kegiatan praktikumdi laboratorium diperoleh nilai pre-test dengan rata-rata51,38 dengan nilai tertinggi 70 dan terendah 20. Sedangkan nilai post-test memiliki rata-rata 79,31 dengan nilai tertinggi 100 dan terendah 30. Hasil pre-test dan post-test ini menunjukkan adanya kenaikan nilai rata-rata siswa sebesar 54,36\%.
\end{abstract}

Kata Kunci: Alat Peraga Laboratorium, Minat Belajar, Kenaikan Nilai Siswa.

\section{PENDAHULUAN}

Dalam sistem pendidikan Nasional, tujuan instruksional pembelajaran dirumuskan dalam bentuk kompetensi, yakni kemampuan yang harus dicapai setelah siswa mengalami proses pembelajaran dalam satuan pendidikan tertentu. Badan Standar Nasional Pendidikan (BSNP) merumuskan bahwa standar kompetensi lulusan satuan pendidikan adalah kualifikasi kemampuan lulusan yang mencakup pengetahuan, sikap, dan keterampilan pada setiap satuan pendidikan yang terdiri dari satuan pendidikan dasar (SD/MI/SDLB/Paket A, SMP/MTs/ SMPLB/Paket B) dan satuan pendidikan menengah (SMA/MA/SMALB/Paket C, SMK/MAK) (Sanjaya, 2008). Salah satu standar kompetensi lulusan satuan pendidikan tersebut adalah menunjukkan kemampuan memecahkan masalah dalam kehidupan sehari-hari.

Dalam penilaian kompetensi siswa, tidak hanya menilai aspek kognitifnya saja, akan tetapi ada penilaian efektif dan psikomotorik. Penilaian psikomotorik merupakan suatu aktivitas fisika untuk mengukur suatu kemampuan kognitif (Shirran, 2008). Penilaian aktivitas fisik ini bissa dilihat dengan adanya dukungan dari fasilitas sekolah seperti laboratorium. Laboratorium memiliki peranan penting dalam proses belajar mengajar. Konsep yang disampaikan guru di kelas bisa dapat dipahami secara baik dengan adanya pengamatan langsung terhadap fenomena-fenomena alam melalui 
aktivitas di laboratorium. Kegiatan yang terjadi di laboratorium berupa praktikum. Kegiatan praktikum ini biasanya disertai dengan tanya jawab antara guru dengan siswa yang melakukan praktikum. Praktikum ini dapat mendeteksi apakah siswa mempunyai miskonsepsi tentang konsep yang sudah diajarkan guru di kelas (Suparno, 2005).

Menurut W.J.S. Poerwadarminta
laboratorium adalah tempat untuk
mengadakan percobaan (penyelidikan dan
sebagainya) segala sesuatu yang
berhubungan dengan ilmu fisika, kimia dan
sebagainya. Sedangkan laboran adalah orang
(ahli ilmu kimia dan sebagainya) yang
bekerja di laboratorium (Emha, dkk, 2002).
Laboratorium merupakan salah satu sarana
yang harus disediakan oleh penyelenggara
sekolah untuk menunjang kegiatan belajar.
Peralatan yang ada di dalam laboratorium
terdiri dari alat peraga. Alat peraga
merupakan wahana fisik yang alami maupun
buatan mengandang materi pembelajaran.
Alat peraga dalam pengertian terbatas yaitu
sebagai alat bantu pengajaran IPA maupun
matematika dalam proses pembelajaran baik
di SD, SMP maupun SMA.

\begin{tabular}{llr}
\multicolumn{1}{c}{ Praktikum } & merupakan salah & satu \\
perwujudan & kerja ilmiah & dalam \\
pembelajaran. & Salirawati & $(2011)$
\end{tabular}
menjelaskan kegiatan praktikum merupakan percobaan yang ditampilkan oleh guru dalam bentuk demonstrasi, demonstrasi secara kooperatif oleh sekelompok siswa, maupun percobaan dan observasi oleh siswa. Kegiatan tersebut dapat berlangsung di laboratorium atau di tempat lain. Trisnawati (2011) mengemukakan agar kegiatan praktikum berjalan sesuai tujuan yang diinginkan, membutuhkan sarana laboratorium yang memadai dan sebuah bahan ajar yang relevan, antara lain dalam bentuk buku panduan praktikum. Petunjuk praktikum diperlukan agar kegiatan praktikum dapat berjalan lancar, tujuan utama dapat tercapai, harus berisi keselamatan kerja untuk memperkecil resiko kecelakaan yang mungkin terjadi dan lainlain.

Salah satu sekolah tingkat satuan dasar yang ada di kota Medan adalah SMP Swasta Islam Terpadu (SMPIT) IQRA'. SMPIT IQRA' ini berada di Jalan Bilal Gg Makmur, Lingkungan I kelurahan Sari Rejo, Kecamatan Medan Polonia, Kota Medan, Propinsi Sumatera Utara. Saat ini SMPIT IQRA' memiliki siswa sebanyak 95 orang yang terdiri dari empat kelas yaitu kelas VII A dan B, VIII dan IX. Akan tetapi sekolah ini belum memiliki laboratorium IPA sebagai sarana pembelajaran yang komprehensif. Untuk itu, kegiatan pengabdian kepada masyarakat ini bertujuan untuk mengoptimalkan laboratorium IPA dengan memberikan alat praktikum sederhana dan mengadakan pembelajaran berbasis praktikum sederhana untuk meningkatkan minat belajar siswa.

\section{METODE PELAKSANAAN}

Adapun metode pelaksanaan kegiatan pengabdian kepada masyarakat ini adalah:

a. Survey awal, yaitu peninjauan lokasi mitra dengan menggali informasi tentang fasilitas apa saja yang sudah dimiliki sekolah serta apa saja yang belum dan sangat dibutuhkan sekolah untuk mendukung proses belajar mengajar. Sehingga tujuan pendidikan nasional berupa pencapaian kompetensi siswa dapat terwujud.

b. Penyediaan alat peraga dan penunjang praktikum di laboratorium. Dalam tahap ini, tim pelaksana mendiskusikan hal-hal apa saja yang akan diberikan untuk mendukung fasilitas laboratorium sekolah serta memperlancar kegiatan proses belajar mengajar.

c. Praktikum sederhana di laboratorium. Pada tahap ini siswa akan diberikan pretest dan post-test sebelum praktikum dilaksanakan. Kegiatan ini ditujukan untuk melihat minat belajar siswa dengan metode praktikum sederhana dengan adanya peningkatan hasil posttest dibandingkan pre-test. 
d. Pembuatan buku penuntun praktikum sederhana di laboratorium sains. Dalam tahap ini tim pelaksana menyusun dan merancang buku panduan praktikum sederhana yang sesuai dengan topik pembelajaran di SMP Swasta Islam Terpadu IQRA' Medan.

\section{HASIL DAN PEMBAHASAN}

Pertama sekali Tim pengabdian masyarakat melakukan survey awal langsung ke sekolah SMP Swasta Islam Terpadu IQRA'diJalan Bilal Gg Makmur, Lingkungan I kelurahan Sari Rejo, Kecamatan Medan Polonia, Kota Medan. Tim berdiskusi dengan mitra mengenai ruangan laboratorium serta peralatan laboratorium yang sudah dimiliki oleh sekolah dan yang dibutuhkan oleh sekolah.

Setelah itu tim memberikan alat-alat peraga laboratorium IPA dan memberikan beberapa poster untuk diletakkan di laboratorium. Alat-alat peraga praktikum IPA ini diantaranya KIT mekanika, KIT listrik, gelas ukur, gelas kimia, enlemeyer, kertas lakmus, larutan indikator $\mathrm{pH}$, dll. Alat peraga yang diberikan ke sekolah dapat dilihat pada Gambar 1.

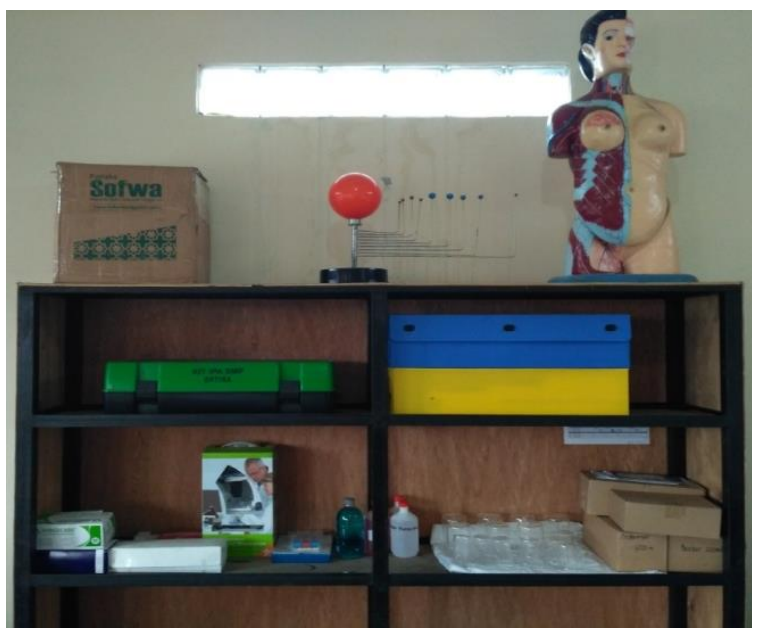

Gambar 1. Alat-alat Laboratorium dari Tim Pengabdian kepada Masyarakat

Selanjutnya Tim melakukan sosialisasi penggunaan peralatan laboratorium dengan memberikan materi pelajaran IPA dan melakukukan praktikum sederhana. Materi pelajaran yang dipilih adalah Larutan Asam Basa. Tim menjelaskan tentang larutan, sifatsifat larutan, asam dan basa serta contohnya dalam kehidupan sehari-hari. Kegiatan ini dapat dilihat pada Gambar 2.

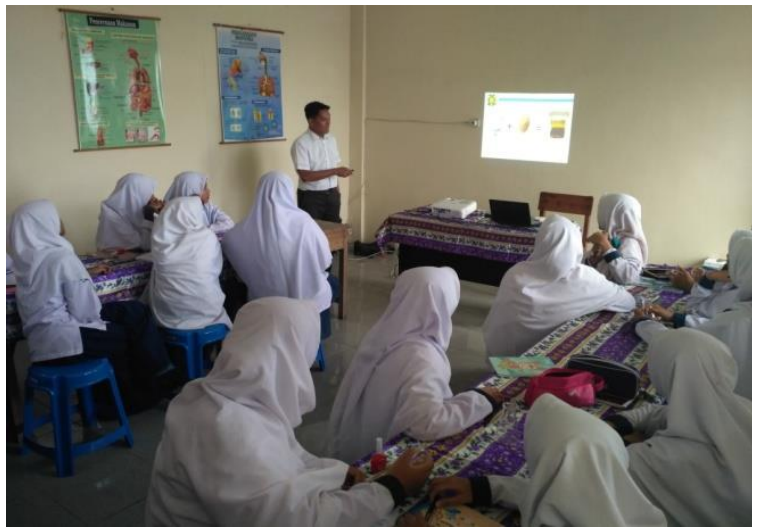

Gambar 2. Kegiatan Sosialisasi Penggunaan Alat-alat Laboratorium

Untuk mengetahui minat belajar siswa meningkat dengan adanya pembelajaran melalui metode praktikum sederhana di laboratorium, Tim membuat pre-test dan post-test. Siswa diberikan soal pre-test mengenai larutan asam dan basa sebanyak 10 soal. Setelah diberikan pre-test Tim menjelaskan materi tentang larutan asam dan basa dengan melakukan percobaan sederhana menggunakan larutan minuman yang ada di sekitar siswa. Seluruh siswa sangat antusias melakukan percobaan sederhana ini. Tidak satupun dari siswa tersebut yang diam dan tidak memperhatikan. Siswa bekerjasama dengan kelompok mereka masing-masing. Kegiatan ini dapat dilihat pada Gambar 3. 


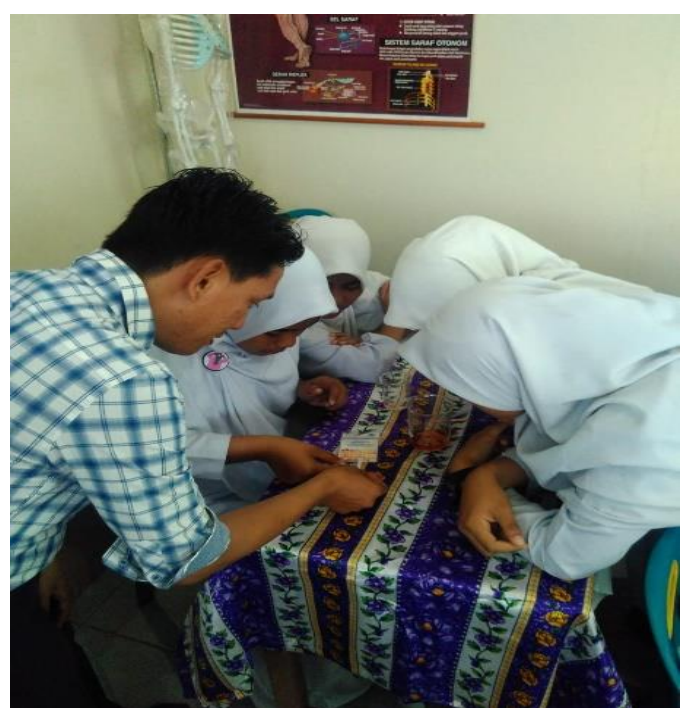

Gambar 3. Kegiatan Percobaan Sederhana di Laboraotrium.

Setelah kegiatan percobaan sederhana di laboratorium, siswa diberikan soal post-test untuk mengukur pemahaman siswa terhadap materi larutan asam dan basa. Soal post-test ini juga terdiri dari 10 soal yang soalnya berbeda dari soal pre-test. Hasil pre-test dan post-test siswa dapat dilihat pada Gambar 4 (a dan b).

Dari diagram pada Gambar 4 tersebut terlihat adanya peningkatan nilai siswa. Pada saat pre-test rata-rata nilai siswa 51,38 dengan nilai tertinggi 70 dan terendah 20 . Sedangkan nilai post-testmemiliki rata-rata 79,31 dengan nilai tertinggi 100 dan terendah 30. Hasil pre-test dan post-test ini menunjukkan adanya kenaikan nilai rata-rata siswa sebesar $54,36 \%$.

(a)

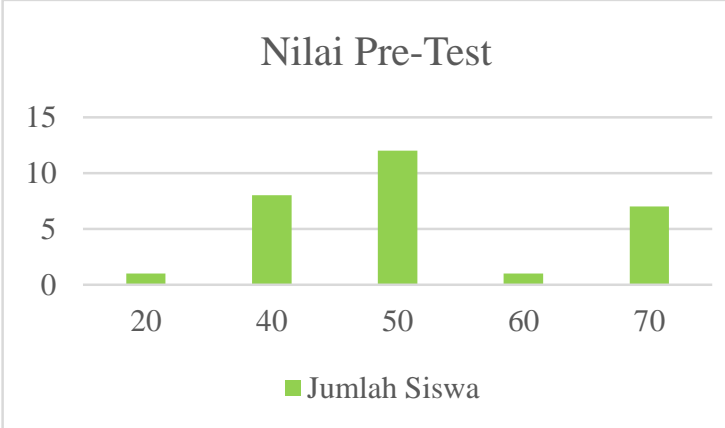

(b)

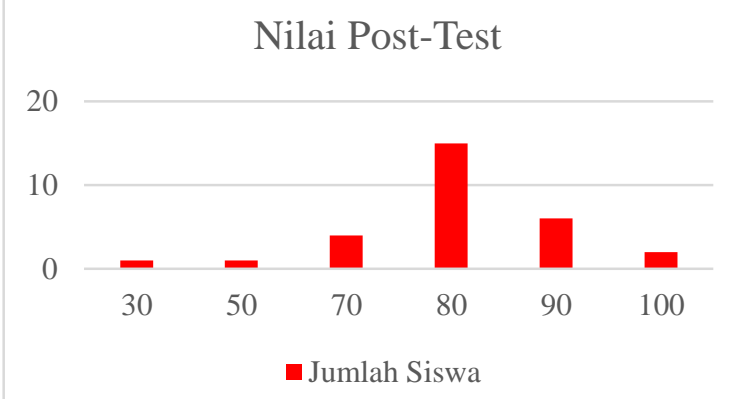

Gambar 4. (a) Hasil Pre-test dan (b) Hasil Post-test Siswa pada Materi Larutan Asam dan Basa

Kebutuhan akan adanya buku penuntun praktikum menjadi salah satu penunjang suksesnya kegiatan praktikum di laboratorium. Untuk itu Tim pengabdian kepada masyarakat membuat buku panduan praktikum IPA sederhana di laboratorium. Buku panduan ini akan digunakan siswa saat kegiatan belajar mengajar di laboratorium.

\section{KESIMPULAN}

Dari kegiatan ini dapat ditarik kesimpulan bahwa keberadaan alat peraga di laboratorium sangat dibutuhkan karena dapat membuat para siswa lebih mudah memahamai teori yang diajarkan oleh para guru saat berada di dalam kelas serta menarik minat belajar para siswa dalam bidang sains. Hasil kegiatan ini menunjukkan adanya peningkatan nilai rata-rata siswa sebesar $54,36 \%$ dari nilai rata-rata pre-test sebesar 51,38 dan post-test 79,31.

\section{UCAPAN TERIMA KASIH}

Kegiatan pengabdian masyarakat yang telah dilaksanakan telah dapat diselesaikan dengan dan didapat hasil yang diharapkan dapat diadopsi oleh masyarakat. Dalam pelaksanaan kegiatan ini, tim peneliti banyak mendapat bantuan dari bebagai kalangan, sehingga kegiatan pengabdian ini dapat terlaksana. Sehubungan dengan hal tersebut, tim peneliti mengucapkan terima kasih kepada LPPM USU yang telah membiayai kegiatan ini 


\section{DAFTAR PUSTAKA}

Emha, Saleh H.,dkk. 2002.Pedoman Penggunaan Laboratorium Sekolah. Bandung: PT Remaja Rosdakarya.

Salirawati, D. 2011. Materi Pelatihan Kepala Laboratorium Kimia bagi Guru-Guru Kimia Kabupaten Kulon Progo. Disampaikan di LaboratoriumFMIPA UNY Yogyakarta, 1 Oktober 2011.

Sanjaya, Wina. 2008. Strategi Pembelajaran Berorientasi Standar Proses Pendidikan.Jakarta: Kencana Prenada Media Group.

Shirran, Alex. 2008. Evaluating StudentsMengevaluasi Siswa. Jakarta: Grasindo.

Suparno, Paul. 2005. Miskonsepsi dan Perubahan Konsep Pendidikan Fisika. Jakarta: Grasindo.

Trisnawati, E. 2011. Pengembangan Petunjuk Praktikum Biologi Materi Struktur Sel dan Jaringan Berbasis Empat Pilar Pendidikan. Skripsi. Semarang: Universitas Negeri Semarang. 